\title{
Serum level of miR-217 predicts prognostic outcome for osteosarcoma patients in China
}

\author{
Lei ZHANG ${ }^{1 *}$ (D), Bofeng $\mathrm{CHEN}^{2}$, Peishan GUAN , Zheng ZHANG ${ }^{4}$
}

\begin{abstract}
In this study, we aimed to investigate the expression of miR-217 in osteosarcoma and adjacent tissues, and its relationship with clinical features, and thus provide a scientific basis for the diagnosis and treatment of osteosarcoma. Sixty patients with osteosarcoma who underwent radical osteosarcoma resection in our hospital in China from January to December 2015 were selected. Real-time reverse transcription PCR (qRT-PCR) was used to detect the expression of miR-217 in osteosarcoma and parasarcoma tissues. Its correlation with clinical data and prognosis of patients was analyzed. Our results showed that the average expression level of miR-217 in osteosarcoma tissues $(2.94 \pm 0.79)$ was higher than that of parasarcoma tissues $(2.14 \pm 0.66)$ $(\mathrm{P}<0.05)$. The difference between the expression level of miR-217 in osteosarcoma tissue and pathological grade $(\mathrm{P}=0.034)$ and clinical stage $(\mathrm{P}=0.007)$ was statistically significant. Cox multivariate analysis showed that clinical stage $(\mathrm{HR}=4.135,95 \%$ $\mathrm{CI}=1.682-6.236)$ and $\mathrm{miR}-217(\mathrm{HR}=3.764,95 \% \mathrm{CI}=1.572-5.921)$ are independent risk factors that affect the prognosis of osteosarcoma $(\mathrm{P}<0.05)$. In conclusion, miR-217 plays a key regulatory role in the occurrence and progression of osteosarcoma. Serum miR-217 levels can predict the prognosis of osteosarcoma patients.
\end{abstract}

Keywords: oteosarcoma; miR-217; prognosis.

Practical Application: Osteosarcoma is a kind of malignant bone tumor that more commonly occurs in adolescents or children under 20 years old. Our results show that miR-217 plays a key regulatory role in the occurrence and progression of osteosarcoma. Serum miR-217 levels can predict the prognosis of osteosarcoma patients.

\section{Introduction}

Osteosarcoma is a kind of malignant bone tumor that more commonly occurs in adolescents or children under 20 years old (Verschoor et al., 2020; Younis et al., 2019; Takeuchi et al., 2019). It is the most common among malignant bone tumors in children, about $5 \%$ of children's tumors (Kopp et al., 2019; Guenther et al., 2018). Osteosarcoma mainly occurs in the distal femur and the proximal metaphysis of the tibia. Osteosarcoma is a highly aggressive tumor that is most likely to metastasize to the lungs, it develops from the interstitial cell line (Haralambiev et al., 2020; Siontis et al., 2020). The rapid growth of the tumor is due to the formation of tumor bone-like tissue and bone tissue directly or indirectly through the cartilage stage. Under the influence of external factors (such as viruses), the weight-bearing bones of the lower limbs mutate the cells, which may be related to the formation of osteosarcoma (Kurelac et al., 2019). The typical osteosarcoma originates in the bone, and another completely different type is the osteosarcoma juxtaposed with the cortical bone, which originates from the outer membrane of the bone and nearby connective tissue (Banerjee \& Bose, 2019; Oliveira et al., 2018).

At present, the main treatment plan for osteosarcoma is primary tumor resection combined with preoperative and postoperative chemotherapy, which increases the 5-year survival rate of osteosarcoma patients to $60 \%$ to $70 \%$ (Marec-Berard et al., 2020; Schott et al., 2018; Vaseenon et al., 2017). It is reported that high protein diet has a certain effect on postoperative nursing of patients with osteosarcoma (Dias et al., 2020; Cordeiro et al., 2020; Gavião et al., 2021; Zhou et al., 2021). In recent years, the treatment strategy for osteosarcoma has been greatly improved, but the overall survival of osteosarcoma patients is still not optimistic, which is closely related to the relatively low clinical early diagnosis rate (Lin et al., 2019; Sugiura et al., 2018). Therefore, it is urgent to discover and identify new molecular biomarkers for early diagnosis of osteosarcoma, and these new discoveries will have a certain impact on the treatment strategy of osteosarcoma.

About $80 \%$ of the genes in the human genome can be transcribed into RNA, but only $2 \%$ of the genes can eventually be encoded into proteins (Pan et al., 2020). These RNAs that cannot be translated are called non-coding RNAs (Zhao et al., 2019). Micro non-coding RNAs (microRNAs, miRNAs) are important members of non-coding RNAs (Lin et al., 2019; Wang et al., 2019), which are a type of short-chain non-coding RNAs encoded by endogenous genes, it can combine with the 
target gene transcript to perform gene transcriptional regulation (Fellenberg et al., 2019). miRNA can play a role in suppressing or promoting cancer by targeting and regulating genes related to tumor cell differentiation, proliferation, apoptosis and metastasis. More and more studies have shown that miRNA expression is closely related to the prognosis of osteosarcoma patients. At present, studies have confirmed that several miRNAs have played an important role in the formation of osteosarcoma, such as miR-150, miR-496, miR-27a, etc. (Ye et al., 2020; Lin et al., 2018), miR-217 is abnormally expressed in various tumors such as breast cancer, gastric cancer, liver cancer, and affects the proliferation, migration and invasion ability of tumor cells (Zhou et al., 2017; Safaralizadeh et al., 2019), but the expression of miR-217 in osteosarcoma is still unclear. This study mainly explored the expression of miR-217 in osteosarcoma, and evaluated the relationship between miR-217 and various pathological features, and thus provide a scientific basis for the diagnosis and treatment of osteosarcoma.

\section{Materials and method}

\subsection{Collection of clinical data}

A total of 60 patients with osteosarcoma who underwent radical osteosarcoma resection in our hospital in China from January to December 2015 were collected. The average age of participants was (17.6 \pm 3.5$)$ years old. Enneking staging: 22 cases in stage I, 25 cases in stage II, and 13 cases in stage III. 39 cases were low grade malignant and 21 cases were highly malignant. All patients had no history of radiotherapy and chemotherapy before surgery. All cases have first-level pathological diagnosis support. Each patient's tissue specimens were osteosarcoma and its nearby tissues ( $\geq 5 \mathrm{~cm}$ from the lesion, confirmed by pathology without tumor cell infiltration), and the tissues were obtained within 10 minutes after surgical resection and stored at $-80^{\circ} \mathrm{C}$. The reagents and instruments used in the laboratory mainly include: miRNeasy extraction kit (Kang Wei Century, Beijing), miRNA reverse transcription kit (Tiangen Biochemical Company, Beijing), fluorescent quantitative PCR kit (Novizan, Beijing), Biotek Epoch micro nucleic acid quantifier was purchased from Biotek in the United States, and 7500 fluorescent quantitative PCR instrument was purchased from ABI.

\subsection{RNA extraction and reverse transcription}

The primer sequences of the primer design software Primer Premier5.0 were used to design the primer sequences of miR-217 and U6. The specific sequences are as follows: hasmir-217-5p: 5'-TAGCAC-CATCTGAAATCGGTTA-3 '; U6: 5'-GCTTCGGCAG-CACATATACTAAA-3'. This sequence was synthesized by Shanghai Biotech Co., Ltd.

The total RNA was extracted using the TRIzol method, and the operation was performed according to the instruction manual of the TRIzol (Sigma) kit. Spectrophotometry was used to quantify RNA. The RNA was reverse transcribed according to the instructions of the PrimeScript RT Master Mix (Takara, Shiga, Japan) RNA reverse transcription kit. In the reverse transcription reaction system, total RNA is $1 \mu \mathrm{g}, 2 \times \mathrm{RTmix}$
$10 \mu \mathrm{L}$, mix $2 \mu \mathrm{L}$, oligo dNTPs $1 \mu \mathrm{L}$, random hexamers $1 \mu \mathrm{L}$, and total system $20 \mu \mathrm{L} .25^{\circ} \mathrm{C} 5 \mathrm{~min}, 50^{\circ} \mathrm{C} 15 \mathrm{~min}, 85^{\circ} \mathrm{C} 5 \mathrm{~min}$, reverse transcription to form cDNA.

\section{3 qRT-PCR detection}

miR-217 was tested with AceQ qPCR SYBR Green Master Mix (Novizan, USA) for miR-217 and U6, and the real-time PCR system was $20 \mu \mathrm{L}$. Reverse transcription product $2 \mu \mathrm{L}$, forward primer $2 \mu \mathrm{L}$, reverse primer $2 \mu \mathrm{L}, 2 \times \operatorname{mix} 10 \mu \mathrm{L}$, pure water $4 \mu \mathrm{L}$. 1 cycle includes $95^{\circ} \mathrm{C} 30$ s, $95^{\circ} \mathrm{C} 5$ s and $60{ }^{\circ} \mathrm{C} 30 \mathrm{~s}$, a total of 40 cycles. All samples were repeated 3 times. U6 was used as an internal reference to calibrate the $\mathrm{Ct}$ value of each sample miR-217, and $2-\Delta \mathrm{Ct}$ was used to indicate the relative gene expression level.

\subsection{Statistical analysis}

SPSS 22.0 software was used for data analysis. Quantitative data is expressed as mean \pm standard deviation $(M \pm S D)$, and qualitative data is expressed as rate (\%). Paired sample t test was used to compare miR-217 in osteosarcoma tissue. The KaplanMeier method is used for the survival function. Cox regression was used to analyze the hazard ratio and $95 \%$ confidence interval, and analyze the influence of various factors on the prognosis of osteosarcoma. $\mathrm{P}<0.05$ was considered statistically significant.

\section{Results}

\section{1 miR-217 expression}

Taking the tissue samples near the osteosarcoma as the reference value, the $2-\Delta \mathrm{Ct}$ value was analyzed by paired sample $\mathrm{t}$ test. The average expression level of miR-217 in osteosarcoma tissue was (2.94 \pm 0.79$)$, which was higher than that of parasarcoma tissue $(2.14 \pm 0.66)$, the difference was statistically significant $(t=3.958, P<0.05)$ (see Figure 1$)$.

\subsection{The relationship between $\mathrm{miR}-217$ and clinicopathological characteristics}

The expression level of miR-217 in osteosarcoma tissue was $(3.02 \pm 0.86)$ in the group under 18 years old, and $(2.87 \pm 0.61)$ in the group under 18 years old and above. The expression level

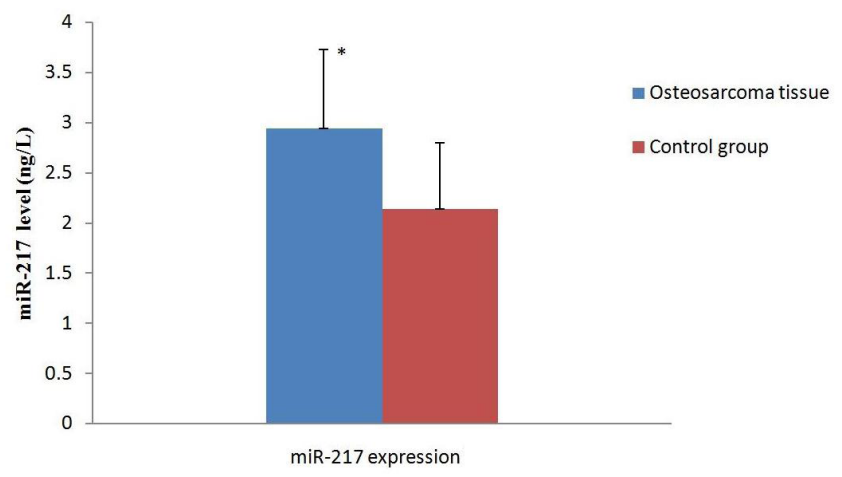

Figure 1. miR-217 expression ( ${ }^{*}$ compared with control group, $\left.P<0.05\right)$. 
of miR-217 in osteosarcoma tissue was $(2.72 \pm 0.79)$ in the male group and $(3.28 \pm 0.85)$ in the female group. The expression level of miR-217 in osteosarcoma tissue was $(2.73 \pm 0.72)$ in the group without tumor family history and $(3.21 \pm 0.91)$ in the group with tumor family history. The expression level of miR-217 in osteosarcoma tissue was not statistically different between different age groups, different gender groups, and the family history of tumors $(P>0.05)$.

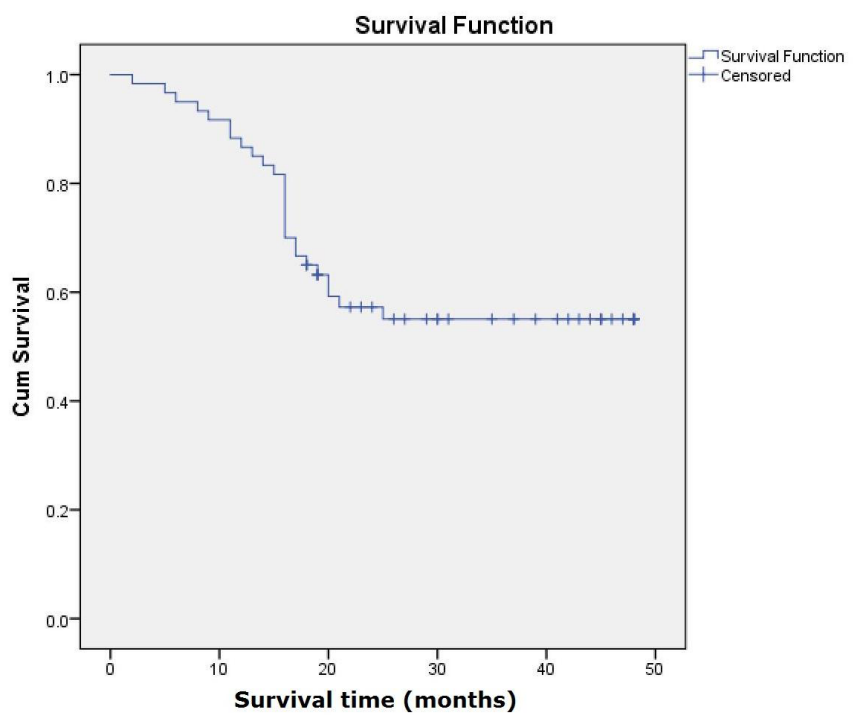

Figure 2. miR-217 and prognosis of osteosarcoma patients.
The expression level of miR-217 in osteosarcoma tissue was $(2.66 \pm 0.69)$ in the pathological grade of low-grade malignant group and $(3.45 \pm 0.82)$ in the pathological grade of low-grade malignant group. The expression level of miR-217 in osteosarcoma tissue was $(2.48 \pm 0.71)$ in the clinical staging group below stage III and $(3.45 \pm 0.87)$ in the clinical stage staging group and above. The difference between the expression level of miR-217 in osteosarcoma tissue and pathological grade $(t=-2.169, P=0.034)$ and clinical stage $(t=-2.788, P=0.007)$ was statistically significant. The statistical analysis results are shown in Table 1.

\subsection{The relationship between miR-217 and patient prognosis}

The last follow-up time of this study is December 2019. The study cohort was followed up for 48 months. 34 of 60 patients relapsed and 26 died, all of whom died of recurrence and metastasis. Among osteosarcoma patients, the median survival time of miR-217 patients was 20.5 months (see Figure 2). Cox univariate analysis showed that pathological grade, clinical stage, and miR-217 expression were related to overall survival (OS). Cox multivariate analysis showed that clinical stage $(H R=4.135,95 \% C I=1.682-6.236)$ and miR-217 $(H R=3.764,95 \% C I=1.572-5.921)$ are independent risk factors that affect the prognosis of osteosarcoma $(P<0.05)$. The statistical analysis results are shown in Table 2.

\section{Discussion}

Osteosarcoma is a common primary malignant tumor of bone, it occurs in the metaphysis of long bones, which is one

Table 1. Correlation between miR-217 expression and clinical data of osteosarcoma patients.

\begin{tabular}{|c|c|c|c|c|}
\hline Variables & $n$ & miR-217 expression level & $t$ & $P$ \\
\hline \multicolumn{5}{|l|}{ Age(years) } \\
\hline$<18$ & 26 & $3.02 \pm 0.86$ & 0.458 & 0.649 \\
\hline$\geq 18$ & 34 & $2.87 \pm 0.61$ & & \\
\hline \multicolumn{5}{|l|}{ Gender } \\
\hline Male & 37 & $2.72 \pm 0.79$ & -1.499 & 0.139 \\
\hline Female & 23 & $3.28 \pm 0.85$ & & \\
\hline \multicolumn{5}{|l|}{ Family history of cancer } \\
\hline None & 35 & $2.73 \pm 0.72$ & -1.319 & 0.192 \\
\hline Yes & 25 & $3.21 \pm 0.91$ & & \\
\hline \multicolumn{5}{|l|}{ Pathological grade } \\
\hline Low grade malignancy & 39 & $2.66 \pm 0.69$ & -2.169 & 0.034 \\
\hline High grade malignancy & 21 & $3.45 \pm 0.82$ & & \\
\hline \multicolumn{5}{|l|}{ Clinical stage } \\
\hline$<$ III & 32 & $2.48 \pm 0.71$ & -2.788 & 0.007 \\
\hline$\geq$ III & 28 & $3.45 \pm 0.87$ & & \\
\hline
\end{tabular}

Table 2. Univariate and multivariate analysis of the overall survival of osteosarcoma patients.

\begin{tabular}{|c|c|c|c|c|c|c|}
\hline \multirow{2}{*}{ Variables } & \multicolumn{3}{|c|}{ Univariate analysis } & \multicolumn{3}{|c|}{ Multivariate analysis } \\
\hline & $H R$ & $95 \% C I$ & $P$ & $H R$ & $95 \% C I$ & $P$ \\
\hline Age & 0.715 & $0.424-1.516$ & 0.351 & & & \\
\hline Gender & 1.284 & $0.895-2.913$ & 0.089 & & & \\
\hline Pathological grade & 2.565 & $0.807-3.881$ & 0.477 & & & \\
\hline Clinical stage & 3.227 & $1.254-5.419$ & 0.041 & 4.135 & $1.682-6.236$ & 0.035 \\
\hline miR-217 & 5.548 & $3.311-6.855$ & 0.024 & 3.764 & $1.572-5.921$ & 0.021 \\
\hline
\end{tabular}


of the main causes of cancer-related deaths in children and adolescents (Jiang et al., 2017a; Cuscino et al., 2019). At present, the etiology of osteosarcoma is unclear. The risk factors of the disease include history of radiotherapy or chemotherapy, Paget disease or other benign bone lesions, and hereditary diseases (including hereditary retinoblastoma, Lifraumeni syndrome, Rothmund-Thomson syndrome, Bloom and Werner syndrome, etc.) (Jiang et al., 2017b). Many factors affect the entire disease process and outcome, including age, tumor volume, tumor location, surgical margin, histological response to preoperative chemotherapy, and interval between recurrence-free (Cai et al., 2017; Denaro et al., 2017).

Although the methods of treating osteosarcoma have been continuously developed, the 5-year survival rate of patients with osteosarcoma is still very low, which is related to no obvious progress in the early diagnosis of osteosarcoma in recent years (Yang et al., 2017). Therefore, early diagnosis is a necessary condition for effectively improving the survival prognosis of patients. With the continuous deepening of the understanding of the occurrence and development of osteosarcoma, exploring the mechanisms regulating the occurrence and metastasis of osteosarcoma has gradually become a research hotspot (Yang et al., 2019; Tuohy et al., 2019). By studying the signal targets related to the occurrence and metastasis of osteosarcoma, and targeted interventions to determine a more effective treatment plan, it is expected to improve the clinical efficacy and prognosis of osteosarcoma.

In recent years, miRNAs have the potential as biomarkers in cancer (Feng et al., 2020; Dong et al., 2019). Since then, more and more studies have begun to pay attention to the functional analysis of miRNAs. Many results suggest that miRNAs are a new target and prognostic marker for cancer treatment (Liu et al., 2019; Ru et al., 2018). Among more than 1,000 known miRNAs, the miR-217 family is considered to have an important role in the progression of cancer due to its abnormal expression in various tumor tissues. miRNA is an endogenous non-coding ribonucleic acid, which regulates gene expression in a series of mammalian cell processes. At present, the correlation between miRNA and autophagy has become a research hotspot. Many studies have shown that multiple miRNAs are considered to be key epigenetic regulators in tumorigenesis and development, including osteosarcoma (Berlanga et al., 2016; Wang et al., 2020).

Recurrence and metastasis are the main causes of poor prognosis of osteosarcoma (Ma et al., 2020). Accurately predicting patients with a high risk of recurrence, and conducting appropriate monitoring and treatment interventions on patients, is of great significance for improving patient survival rates. This study explored the expression of miR-217 in 60 cases of osteosarcoma and tissues near osteosarcoma, and analyzed the relationship between it and prognosis in combination with case data. The results of this study show that the expression of miR-217 in osteosarcoma is higher than the tissues near osteosarcoma, and can affect the prognosis of patients. Many studies have shown that miR-217 inhibits laryngeal cancer metastasis by repressing AEG-1 and PD-L1 expression (Miao et al., 2017), miR-217 regulates the tumor growth and apoptosis of colorectal cancer by targeting the MAPK signaling pathway (Zhang et al., 2016),
HOTAIR contributes to the growth of liver cancer via targeting miR-217 (Wang et al., 2018), etc. This shows that miR-217, like other miRNAs, has the difference of tissue expression, that is, the expression level is different in different tissues, the role it plays is different, and may even be the opposite.

This study also found that the expression level of miR-217 is related to the pathological grade and clinical stage of the tumor. Pei et al (Pei et al., 2016) found that the incidence of osteosarcoma has a gender difference, and the incidence ratio of men and women is 1.4: 1 . The peak of relapse is in the second 10a after the first incidence. Kaplan-Meier analysis of this study showed that patients with up-regulated miR-217 expression had a poor prognosis. This study believes that this is related to the difference of different tumor tissues and the tissue diversity of miRNAs.

In conclusion, miR-217 plays a key regulatory role in the occurrence and progression of osteosarcoma, serum miR-217 levels can predict the prognosis of osteosarcoma patients, and the clinical application value is high.

\section{Conflict of Interest}

The authors declare that they have no competing interest.

\section{References}

Banerjee, D., \& Bose, S. (2019). Comparative effects of controlled release of sodium bicarbonate and doxorubicin on osteoblast and osteosarcoma cell viability. Mater Today Chem, 12, 200-208. http:// dx.doi.org/10.1016/j.mtchem.2018.11.008. PMid:31938758.

Berlanga, P., Munoz, L., Piqueras, M., Sirerol, J. A., Sánchez-Izquierdo, M. D., Hervás, D., Hernández, M., Llavador, M., Machado, I., Llombart-Bosch, A., Cañete, A., Castel, V., \& Font de Mora, J. (2016). $\mathrm{miR}-200 \mathrm{c}$ and phospho-AKT as prognostic factors and mediators of osteosarcoma progression and lung metastasis. Molecular Oncology, 10(7), 1043-1053. http://dx.doi.org/10.1016/j.molonc.2016.04.004. PMid:27155790.

Cai, A. L., Zeng, W., Cai, W. L., Liu, J. L., Zheng, X. W., Liu, Y., Yang, X. C., Long, Y., \& Li, J. (2017). Peroxiredoxin-1 promotes cell proliferation and metastasis through enhancing Akt/mTOR in human osteosarcoma cells. Oncotarget, 9(9), 8290-8302. http:// dx.doi.org/10.18632/oncotarget.23662. PMid:29492195.

Cordeiro, A. R. R. A., Bezerra, T. K. A., Queiroz, A. L. M., Galvão, M. S., Cavalcanti, M. T., Pacheco, M. T. B., \& Madruga, M. S. (2020). Collagen production from chicken keel bone using acid and enzymatic treatment at a temperature of $30^{\circ} \mathrm{C}$. Food Science and Technology, 40(2), 491-497.

Cuscino, N., Raimondi, L., Luca, A., Carcione, C., Russelli, G., Conti, L., Baldi, J., Conaldi, P. G., Giavaresi, G., \& Gallo, A. (2019). Gathering novel circulating exosomal microrna in osteosarcoma cell lines and possible implications for the disease. Cancers, 11(12), 1924. http:// dx.doi.org/10.3390/cancers11121924. PMid:31816885.

Denaro, L., Longo, U. G., Martino, A. C., Maffulli, N., \& Denaro, V. (2017). Screw migration and oesophageal perforation after surgery for osteosarcoma of the cervical spine. BMC Musculoskeletal Disorders, 18(1), 552. http://dx.doi.org/10.1186/s12891-017-19065. PMid:29284452.

Dias, D. M., Gomes, M., Moreira, M., Natal, D., Silva, R. R., Nutti, M., Matta, S. L., Sant'Ana, H. M. P., \& Martino, H. S. D. (2020). Staple food crops from Brazilian Biofortification Program have high protein 
quality and hypoglycemic action in Wistar rats. Food Science and Technology, 40(1), 140-149. http://dx.doi.org/10.1590/fst.32918.

Dong, S., Xiao, Y., Ma, X., He, W., Kang, J., Peng, Z., Wang, L., \& Li, Z. (2019). miR-193b Increases the chemosensitivity of osteosarcoma cells by promoting FEN1-mediated autophagy. OncoTargets and Therapy, 12, 10089-10098. http://dx.doi.org/10.2147/OTT.S219977. PMid:31819503.

Fellenberg, J., Lehner, B., Saehr, H., Schenker, A., \& Kunz, P. (2019). Tumor Suppressor Function of miR-127-3p and miR-376a-3p in osteosarcoma cells. Cancers, 11(12), 2019. http://dx.doi.org/10.3390/ cancers11122019. PMid:31847321.

Feng, T., Zhu, Z., Jin, Y., Wang, H., Mao, X., Liu, D., Li, Y., Lu, L., \& Zuo, G. (2020). The microRNA7085p/ZEB1/EMT axis mediates the metastatic potential of osteosarcoma. Oncology Reports, 43(2), 491-502. PMid:31894343.

Gavião, E. R., Munieweg, F. R., Czarnobay, M., Dilda, A., Stefani, L. C. M., \& Nespolo, C. R. (2021). Development and characterization of two novel formulations of Labneh cheese of sheep's milk. Food Science and Technology, 41(3), 708-715. http://dx.doi.org/10.1590/fst.20020.

Guenther, L. M., Rowe, R. G., Acharya, P. T., Swenson, D. W., Meyer, S. C., Clinton, C. M., Guo, D., Sridharan, M., London, W. B., Grier, H. E., Ecklund, K., \& Janeway, K. A. (2018). Response Evaluation Criteria in Solid Tumors (RECIST) following neoadjuvant chemotherapy in osteosarcoma. Pediatric Blood \& Cancer, 65(4), e26896. http:// dx.doi.org/10.1002/pbc.26896. PMid:29251406.

Haralambiev, L., Wien, L., Gelbrich, N., Lange, J., Bakir, S., Kramer, A., Burchardt, M., Ekkernkamp, A., Gümbel, D., \& Stope, M. B. (2020). Cold atmospheric plasma inhibits the growth of osteosarcoma cells by inducing apoptosis, independent of the device used. Oncology Letters, 19(1), 283-290. PMid:31897140.

Jiang, C., Yu, M., Xie, X., Huang, G., Peng, Y., Ren, D., Lin, M., Liu, B., Liu, M., Wang, W., \& Kuang, M. (2017b). miR-217 targeting DKK1 promotes cancer stem cell properties via activation of the Wnt signaling pathway in hepatocellular carcinoma. Oncology Reports, 38(4), 2351-2359. http://dx.doi.org/10.3892/or.2017.5924. PMid:28849121.

Jiang, S., Wang, G., \& Dong, Y. (2017a). Endostar combined with chemotherapy in a pediatric osteosarcoma with pulmonary metastasis and malignant pleural effusion. Medicine, 96(51), e9077. PMid:29390436

Kopp, L. M., Womer, R. B., Schwartz, C. L., Ebb, D. H., Franco, V. I., Hall, D., Barkauskas, D. A., Krailo, M. D., Grier, H. E., Meyers, P. A., Wexler, L. H., Marina, N. M., Janeway, K. A., Gorlick, R., Bernstein, M. L., \& Lipshultz, S. E. (2019). Effects of dexrazoxane on doxorubicinrelated cardiotoxicity and second malignant neoplasms in children with osteosarcoma: a report from the Children's Oncology Group. Cardio-Oncology, 5(1), 15. http://dx.doi.org/10.1186/s40959-0190050-9. PMid:32154021.

Kurelac, I., Abarrategi, A., Ragazzi, M., Iommarini, L., Ganesh, N. U., Snoeks, T., Bonnet, D., Porcelli, A. M., Malanchi, I., \& Gasparre, G. (2019). A humanized bone niche model reveals bone tissue preservation upon targeting mitochondrial complex I in pseudoorthotopic osteosarcoma. Journal of Clinical Medicine, 8(12), 2184. http://dx.doi.org/10.3390/jcm8122184. PMid:31835761.

Lin, Q., Han, J., Sun, Q., Wen, L., \& Wang, S. (2019). Functional variant of IL33 is associated with survival of osteosarcoma patients. Journal of Bone Oncology, 20, 100270. http://dx.doi.org/10.1016/j. jbo.2019.100270. PMid:31890491.

Lin, T., Ma, Q., Zhang, Y., Zhang, H., Yan, J., \& Gao, C. (2018). MicroRNA27a functions as an oncogene in human osteosarcoma by targeting CCNG1. Oncology Letters, 15(1), 1067-1071. PMid:29399167.
Liu, Z. J., Chen, S. G., Yang, Y. Z., Lu, S., Zhao, X., Hu, B., \& Zhang, L. (2019). miR-29a inhibits adhesion, migration, and invasion of osteosarcoma cells by suppressing CDC42. International Journal of Clinical and Experimental Pathology, 12(11), 4171-4180. PMid:31933817.

Ma, T., Liu, A., Xu, D., \& Zhang, T. (2020). Mechanisms underlying the promotion of osteosarcoma cell proliferation and invasion by lncRNA PBB12. Oncology Reports, 43(2), 736-746. PMid:31894336.

Marec-Berard, P., Dalban, C., Gaspar, N., Brugieres, L., Gentet, J. C., Lervat, C., Corradini, N., Castex, M. P., Schmitt, C., Pacquement, H., Tabone, M. D., Brahmi, M., Metzger, S., Blay, J. Y., \& Pérol, D. (2020). A multicentric randomized phase II clinical trial evaluating high-dose thiotepa as adjuvant treatment to standard chemotherapy in patients with resectable relapsed osteosarcoma. European Journal of Cancer, 125, 58-68. http://dx.doi.org/10.1016/j.ejca.2019.11.007.

Miao, S., Mao, X., Zhao, S., Song, K., Xiang, C., Lv, Y., Jiang, H., Wang, L., Li, B., Yang, X., Yuan, Z., Xiu, C., Meng, H., \& Sun, J. (2017). miR-217 inhibits laryngeal cancer metastasis by repressing AEG-1 and PD-L1 expression. Oncotarget, 8(37), 62143-62153. http://dx.doi. org/10.18632/oncotarget.19121. PMid:28977933.

Oliveira, J. M. P. F., Pacheco, A. R., Coutinho, L., Oliveira, H., Pinho, S., Almeida, L., Fernandes, E., \& Santos, C. (2018). Combination of etoposide and fisetin results in anti-cancer efficiency against osteosarcoma cell models. Archives of Toxicology, 92(3), 1205-1214. http://dx.doi.org/10.1007/s00204-017-2146-z. PMid:29270805.

Pan, Z., Wu, C., Li, Y., Li, H., An, Y., Wang, G., Dai, J., \& Wang, Q. (2020). LncRNA DANCR silence inhibits SOX5-medicated progression and autophagy in osteosarcoma via regulating miR-216a-5p. Biomedicine and Pharmacotherapy, 122, 109707. http://dx.doi.org/10.1016/j. biopha.2019.109707. PMid:31918278.

Pei, Y. F., Lei, Y., \& Liu, X. Q. (2016). MiR-29a promotes cell proliferation and EMT in breast cancer by targeting ten eleven translocation 1. Biochimica et Biophysica Acta, 1862(11), 2177-2185. http://dx.doi. org/10.1016/j.bbadis.2016.08.014. PMid:27555295.

Ru, N., Zhang, F., Liang, J., Du, Y., Wu, W., Wang, F., \& Liu, X. (2018). miR-564 is down-regulated in osteosarcoma and inhibits the proliferation of osteosarcoma cells via targeting Akt. Gene, 645, 163 169. http://dx.doi.org/10.1016/j.gene.2017.12.028. PMid:29248580.

Safaralizadeh, R., Ajami, N., Nemati, M., Hosseinpourfeizi, M., Azimzadeh Isfanjani, A., \& Moaddab, S. Y. (2019). Disregulation of miR-216a and miR-217 in gastric cancer and their clinical significance. Journal of Gastrointestinal Cancer, 50(1), 78-83. http://dx.doi.org/10.1007/ s12029-017-0019-6. PMid:29177609.

Schott, C. R., Tatiersky, L. J., Foster, R. A., \& Wood, G. A. (2018). Histologic grade does not predict outcome in dogs with appendicular osteosarcoma receiving the standard of care. Veterinary Pathology, 55(2), 202-211. http://dx.doi.org/10.1177/0300985817747329. PMid:29284372.

Siontis, B. L., McHugh, J. B., Roberts, E., Zhao, L., Thomas, D. G., Owen, D., Baker, L. H., Biermann, J. S., Schuetze, S. M., \& Chugh, R. (2020). Differential outcomes and biologic markers of radiation-associated vs. sporadic osteosarcoma: a single-institution experience. Frontiers in Oncology, 9, 1523. http://dx.doi.org/10.3389/fonc.2019.01523. PMid:32039013.

Sugiura, Y., Kanda, H., Motoi, N., Nomura, K., Inamura, K., Okada, E., Matsumoto, H., Shimoji, T., Matsumoto, S., Nakayama, J., Takazawa, Y., Ishikawa, Y., \& Machinami, R. (2018). Osteosarcoma arising in fibrous dysplasia, confirmed by mutational analysis of GNAS gene. Pathology, Research and Practice, 214(2), 318-324. http://dx.doi. org/10.1016/j.prp.2017.10.018. PMid:29268950.

Takeuchi, A., Yamamoto, N., Hayashi, K., Matsubara, H., Miwa, S., Igarashi, K., \& Tsuchiya, H. (2019). Joint-preservation surgery for 
pediatric osteosarcoma of the knee joint. Cancer and Metastasis Reviews, 38(4), 709-722. http://dx.doi.org/10.1007/s10555-01909835-z. PMid:31807972.

Tuohy, J. L., Shaevitz, M. H., Garrett, L. D., Ruple, A., \& Selmic, L. E. (2019). Demographic characteristics, site and phylogenetic distribution of dogs with appendicular osteosarcoma: 744 dogs (2000-2015). PLoS One, 14(12), e0223243. http://dx.doi.org/10.1371/journal. pone.0223243. PMid:31887114.

Vaseenon, T., Saengsin, J., Kaminta, A., Pattamapaspong, N., Settakorn, J., \& Pruksakorn, D. (2017). Ankle ligament reconstruction after wide resection of the osteosarcoma of the distal fibula: a case report. BMC Research Notes, 10(1), 769. http://dx.doi.org/10.1186/s13104017-3097-4. PMid:29282106.

Verschoor, A. J., Speetjens, F. M., Dijkstra, P. D. S., Fiocco, M., Sande, M. A. J., Bovée, J. V. M. G., \& Gelderblom, H. (2020). Single-center experience with ifosfamide monotherapy as second-line treatment of recurrent/metastatic osteosarcoma. The Oncologist, 25(4), e716-e721. http://dx.doi.org/10.1634/theoncologist.2019-0528. PMid:32297446.

Wang, J. Y., Yang, Y., Ma, Y., Wang, F., Xue, A., Zhu, J., Yang, H., Chen, Q., Chen, M., Ye, L., Wu, H., \& Zhang, Q. (2020). Potential regulatory role of IncRNA-miRNA-mRNA axis in osteosarcoma. Biomedicine and Pharmacotherapy, 121, 109627. http://dx.doi.org/10.1016/j. biopha.2019.109627. PMid:31810120.

Wang, L. P., Wang, J. P., \& Wang, X. P. (2018). HOTAIR contributes to the growth of liver cancer via targeting miR-217. Oncology Letters, 15(5), 7963-7972. http://dx.doi.org/10.3892/ol.2018.8341. PMid:29849802.

Wang, L., Zhang, G. C., Kang, F. B., Zhang, L., \& Zhang, Y. Z. (2019). hsa_circ0021347 as a Potential Target Regulated by B7-H3 in Modulating the Malignant Characteristics of Osteosarcoma. BioMed Research International, 2019, 9301989. http://dx.doi. org/10.1155/2019/9301989. PMid:31950059.

Yang, P., Gilg, M., Evans, S., Totti, F., Stevenson, J., Jeys, L., \& Parry, M. (2019). Survival of osteosarcoma patients following diagnosis of synchronous skip metastases. Journal of Orthopaedics, 18, 121-125. http://dx.doi.org/10.1016/j. jor.2019.10.003. PMid:32021017.

Yang, Y., Han, L., He, Z., Li, X., Yang, S., Yang, J., Zhang, Y., Li, D., Yang, Y., \& Yang, Z. (2017). Advances in limb salvage treatment of osteosarcoma. Journal of Bone Oncology, 10, 36-40. http://dx.doi. org/10.1016/j.jbo.2017.11.005. PMid:29296558.

Ye, J., Xie, W., Zuo, Y., Jing, G., \& Tong, J. (2020). MicroRNA-496 suppresses tumor cell proliferation by targeting BDNF in osteosarcoma. Experimental and Therapeutic Medicine, 19(2), 14251431. PMid:32010318.

Younis, J. A., Al Antably, I. M., Zamzam, M., Salem, H. T., Zaki, E. M., \& Hassanian, O. A. (2019). Role of (18)F-fluorodeoxyglucose positron emission tomography/computed tomography and magnetic resonance imaging in prediction of response to neoadjuvant chemotherapy in pediatric osteosarcoma. World Journal of Nuclear Medicine, 18(4), 378-388. http://dx.doi.org/10.4103/wjnm.WJNM_52_18. PMid:31933554.

Zhang, N., Lu, C., \& Chen, L. (2016). miR-217 regulates tumor growth and apoptosis by targeting the MAPK signaling pathway in colorectal cancer. Oncology Letters, 12(6), 4589-4597. http://dx.doi.org/10.3892/ ol.2016.5249. PMid:28105166.

Zhao, Z., Lin, X., Tong, Y., \& Li, W. (2019). Silencing lncRNA ZFAS1 or elevated microRNA-135a represses proliferation, migration, invasion and resistance to apoptosis of osteosarcoma cells. Cancer Cell International, 19(1), 326. http://dx.doi.org/10.1186/s12935019-1049-x. PMid:31827400.

Zhou N., Fang B., Yi C., Lan G., He M., Zheng J., Yang X., Pang F. (2021). Research progress of traditional Chinese medicine in the treatment of osteosarcoma. Journal of Traditional Chinese Medicine Oncology, 3(1), 76-81.

Zhou, W., Song, F., Wu, Q., Liu, R., Wang, L., Liu, C., Peng, Y., Mao, S., Feng, J., \& Chen, C. (2017). miR-217 inhibits triple-negative breast cancer cell growth, migration, and invasion through targeting KLF5. PLoS One, 12(4), e0176395. http://dx.doi.org/10.1371/journal. pone.0176395. PMid:28437471. 